\title{
ESTUDO PARA IMPLEMENTAÇÃO DE UM SISTEMA DE APURAÇÃO DE CUSTOS NO CENTRO DE PESQUISAS ONCOLÓGICAS - CEPON
}

\author{
Maristela Zardo \\ Graduada em Administração pela Faculdade Estácio de Sá de Santa Catarina - FESSC \\ (2007). Especialista em Gestão em Saúde Pública pela Faculdade Bagozzi do Paraná \\ (2010). Administradora no Centro de Pesquisas Oncológicas (CEPON). \\ maristelazardo@gmail.com \\ Helio Roberto Hekis \\ Doutor em Engenharia de Produção e Sistemas pela Universidade Federal de Santa \\ Catarina - UFSC (2004). Pesquisador do Laboratório de Inovação Tecnológica em Saúde \\ (LAIS) - Hospital Universitário Onofre Lopes (HUOL). Professor do Departamento de \\ Engenharia de Produção - Universidade Federal do Rio Grande do Norte (UFRN). \\ hekis1963@gmail.com
}

\begin{abstract}
RESUMO
O trabalho tem como objetivo realizar um estudo para a implementação de um sistema de apuração de custos no Centro de Pesquisas Oncológicas (CEPON). Para a realização do estudo utilizou-se a pesquisa bibliográfica para fundamentar e ilustrar o tema proposto, bem como, o método exploratório descritivo para reconhecer a situação da instituição e identificar um sistema de apuração adequado à realidade da organização estudada. A apuração de custos em organizações hospitalares justifica-se pelo aumento na demanda de clientes, o crescimento dos gastos na área da saúde e as limitações decorrentes de orçamentos limitados, onde as organizações necessitam adotar um sistema que forneça informações úteis referentes a custos. Um sistema de apuração de custos pode trazer aos gestores hospitalares informações relevantes ao planejamento, controle e tomada de decisão com vistas à otimização de recursos e manutenção da qualidade no atendimento ao paciente. Como resultados alcançados foram apresentados os principais métodos adotados para a implementação de um sistema de gestão de custos hospitalares que são o custeio direto, custeio por absorção, com apropriação por centro de custos, e o custeio baseado em atividades (ABC). Depende de cada hospital identificar qual o método mais adequado a sua estrutura organizacional. Em relação às considerações finais verificou-se que a implementação de um sistema de apuração de custos hospitalares proporcionará ao CEPON importantes informações gerenciais. No atual contexto organizacional, identificou-se que o recomendável é o método de custeio por absorção, por ser o mais tradicional e que demanda menores investimentos para sua implementação.
\end{abstract}

Palavras-chave: Organizações hospitalares, apuração de custos, custeio por absorção.

\section{STUDY ON IMPLEMENTATION OF A SYSTEM FOR DETERMINATION OF COSTS IN ONCOLOGY RESEARCH CENTER (CEPON)}

\begin{abstract}
This paper aims to conduct a study to implement a system for calculating costs in Oncology Research Center (CEPON). To conduct the study used the literature to support and illustrate the theme, as well as descriptive exploratory method to recognize the
\end{abstract}


institution's situation and identify an appropriate system of assessment to the reality of the organization studied. The calculation of costs in hospital organizations is justified by increased customer demand, growth in spending in health and limitations due to limited budgets, where organizations need to adopt a system that provides useful information regarding costs. A system of verification of costs to hospital managers can bring relevant information to the planning, control and decision making with a view to optimizing resources and maintenance of quality in patient care. Results were presented as the main methods used to implement a management system of hospital costs are the direct costing, absorption costing, with ownership by cost center and activity-based costing (ABC). It depends on each hospital to identify which method best suited to your organizational structure. In relation to the final considerations it was found that the implementation of a system of verification of hospital costs to provide CEPON important management information. In the current organizational context, we identified that the recommended method is the absorption costing, because it is the more traditional and less investment demand for its implementation.

Keywords: Organizations hospital, verification of costs, absorption costing.

\section{ESTUDO PARA IMPLEMENTAÇÃO DE UM SISTEMA DE APURAÇÃO DE CUSTOS NO CENTRO DE PESQUISAS ONCOLÓGICAS - CEPON}

\section{INTRODUÇÃO}

Em meio a um cenário empresarial altamente competitivo, decorrente de fatores como a globalização e aos avanços tecnológicos, as organizações precisam adotar instrumentos gerenciais adequados à adminstração dos recursos utilizados em suas atividades. As organizações hospitalares encontram-se dentro desse ambiente, onde convivem com os mesmos desafios e carecem de uma gestão profissional, sem a qual tornará inviável a manutenção da qualidade no atendimento e a sobrevivência da organização.

Neste contexto, os sistemas de informação de custos hospitalares assumem um papel muito importante, que vai além das necessidades da contabilidade de custos, permitindo a avaliação de resultados, tomada de decisões referentes a investimentos, operacionalização otimizada dos serviços, implementação de melhorias, entre outras.

No entanto, a maioria das organizações na área da saúde só percebeu esta necessidade recentemente. Os hospitais eram vistos como instituições de caridade, com uma estrutura complexa, em que os princípios de administração hospitalar não tinham relevância. Entretanto, devido à dificuldade de gerenciar recursos cada mais limitados, sobretudo em hospitais públicos, despertou-se para a necessidade de gerenciar os custos de modo a racionalizar os gastos.

O Centro de Pesquisas Oncológicas (CEPON), localizado na cidade Florianópolis, objeto de estudo de caso deste artigo tem seu atendimento voltado, basicamente, a pacientes pelo Sistema Único de Saúde (SUS). A área oncológica compreende tratamentos de alto custo. A receita gerada com a produção nem sempre é suficiente para cobrir os gastos incorridos no tratamento e na operacionalização das demais atividades inerentes à manutenção da instituição. Nesse contexto, equilibar receita e despesa é uma tarefa difícil, que demanda observação e controle dos gastos. 
O objetivo geral deste artigo visa apresentar um estudo para implementação de um sistema de apuração de custos hospitalares para o Centro de Pesquisas Oncológicas - CEPON, além de definir, entre os diversos métodos de custeio, o mais adequado à realidade da organização estudada. Associado ao objetivo geral apresenta-se os seguintes objetivos específicos: 1) Identificar os motivos/razões internos que incentivarão a escolha da apresentação de uma metodologia para a gestão de custos; 2) Definir, entre os diversos métodos de custeio, o mais adequado à realidade da organização estudada; 3) Apresentar um estudo para implementação de um sistema de custos hospitalares no CEPON.

Nesse contexto, pode ser percebida a importância de um sistema de gestão de custos hospitalares e o problema de pesquisa a ser investigado será: qual metodologia de apuração de custos é indicada para implementação no Centro de Pesquisas Oncológicas (CEPON)?

A apresentação de uma metodologia adequada de implementação de sistema de apuração de custos será embasada no conhecimento das características da organização e na consulta de literatura pertinente ao assunto.

O artigo está estruturado da seguinte maneira, além desta seção introdutória, a seção 2 apresenta a gestão de custos para unidades de saúde. A seção 3 apresenta argumentos sobre a contabilidade de custos. Na seção 4 apresenta-se os principais métodos de custeio. A seção 5 mostra a implementação de um sistema de apuração de custos no Centro de Pesquisas Oncológicas - CEPON. Na seção 5 apresenta-se os resultados encontrados e a sugestão de método de rateio por centro de custo. Na seção 6 as considerações finais, e por fim as referências

\section{GESTÃO DE CUSTOS PARA UNIDADES DE SAÚDE}

Uma característica comum a todas as organizações de saúde, com e sem fins lucrativos, é o fato de ter que enfrentar a escassez de recursos e a elevação dos custos. Neste sentido, aumentam as preocupações sobre o sistema de gerenciamento, na expectativa de atingir um melhor desempenho, agilidade e diferenciação assistencial (CECÍLIO, 1997; BITTENCOURT, 2007).

Observa-se que esta preocupação é um problema geral para as instituições hospitalares, pois a demanda pelo serviço é alta e crescente, mas os recursos são escassos. Segundo Martins (2007, p. 25), "esta evolução requer um grande desafio para a gerência, pois à medida que os hospitais passam por um processo de modernização, torna-se necessário modernizar as técnicas de administração hospitalar [...]".

Neste contexto, observa-se que o modelo de gestão hospitalar prioriza o atendimento e a eficácia técnica, deixando para segundo plano, as aplicações práticas e a importância das ferramentas administrativas. $\mathrm{O}$ atendimento hospitalar é parte principal do negócio, mas somente se completará quando todo o processo administrativo for adaptado para este fim (CARDOSO, 2006). O processo hospitalar possui um conjunto de atividades que demandam recursos que têm um alto custo. Devido a este fato, os hospitais precisam conhecer seus processos e identificar os recursos envolvidos, por meio do desenvolvimento de uma ferramenta de custos para quantificá-los.

Na perspectiva de Fernandes (1993), o sistema de custo hospitalar tem os seguintes objetivos: reduzir custos, evitar desperdícios de materiais, esforços e mão-de-obra; oferecer 
informações para a tomada de decisões; estabelecer metas inclusive para determinar épocas de substituição de equipamentos e imobilizados; permitir comparação periódica da evolução dos custos; permitir comparação dos custos com as receitas; permitir comparação dos custos com os custos de outras empresas e instituições; dar a conhecer o grau de eficiência e de produção.

De acordo com Nunes e Infante (2002), só é possível medir resultados, relacionando recursos utilizados com metas alcançadas com a implementação de um sistema de apuração de custos. Segundo os autores, os principais objetivos do sistema de custos hospitalares são:

$\checkmark$ Informar a participação de cada setor, ou centro de custo, no gasto total da unidade;

$\checkmark$ Identificar a relação entre gastos realizados por centro de custo e os serviços produzidos, com o objetivo de promover a racionalização administrativa;

$\checkmark$ Detectar variações nos custos dos serviços e identificar suas possíveis causas;

$\checkmark$ Estabelecer rotinas para o processamento das informações relativas à relação recursos versus produção, de modo a subsidiar a projeção de gastos futuros e a elaboração de orçamentos;

$\checkmark$ Fixar valores de referência para os serviços prestados, possibilitando sua utilização como parâmetro de custos para assinaturas de convênios com outras instituiçõos;

$\checkmark$ Aprofundar o conhecimento da estrutura dos recursos em relação aos serviços prestados. Estas informações são fundamentais para a definição de normas operacionais e para a projeção de recursos necessários para absorver à demanda;

$\checkmark$ Fornecer elementos para elaboração ou readequação dos mecanismos administrativos e técnicos de controle interno, seja de recursos humanos ou materiais.

Neste sentido, a apuração e o controle dos custos hospitalares é uma ferramenta importante dentro das instituições hospitalares. A apuração serve de instrumento eficaz de gerência e acompanhamento dos serviços. O controle de custos é utilizado na implantação de medidas corretivas que visem a um melhor desempenho das unidades, servindo como parâmetro para uma redefinição das prioridades, aumento da produtividade e na racionalização do uso de recursos. (ARTMANN e RIVERA, 2003; ROCHA, 2007; CAMACHO e ROCHA, 2008).

\section{A CONTABILIDADE DE CUSTOS}

Um dos desafios para os gestores de pequenas e médias empresas é controlar seus custos de modo que obtenham um resultado econômico favorável. Isto só será possível com a implantação de um sistema de custos que permita encontrar meios confiáveis de avaliação e controle dos custos de cada atividade desenvolvida.

Os custos de uma empresa deverão ser definidos pela contabilidade de custos por processo, por procedimento ou por atividade, uma vez que é ampla e se especializa cada dia mais, principalmente, em sua utilização nas áreas industriais e prestação de serviços. Com relação à contabilidade de custos, Leone $(1992 ; 2000)$ diz que, hoje, a contabilidade de custos passa a ser instrumento imprescindível para os gestores das organizações, especialmente no processo de tomada de decisões. Não é mais uma necessidade, mas sim uma obrigatoriedade para manter se competitiva, pois oferece as informações para mensuração do desempenho do resultado. 
A contabilidade de custos pode ser definida como um instrumento desenvolvido com o objetivo de atingir finalidades específicas e que podem estar relacionadas com o fornecimento de dados de custos para a apuração de lucros, a determinação de rentabilidade e a avaliação de patrimônio, identificando métodos e procedimentos para o controle das operações e atividades executadas, de modo a fornecer informações sobre custos para a tomada de decisões e de planejamento através de processos analíticos (CALLADO e CALLADO, 1998).

Uma das preocupações da contabilidade de custos é atender as necessidades dos gestores, ou seja, gerar informações para a tomada de decisões. Portanto, podem-se destacar três objetivos principais da contabilidade de custos: determinação do lucro da empresa, auxílio ao controle e ajuda às tomadas de decisões.

Martins (2001) destaca que em relação ao controle a principal missão da contabilidade de custos é fornecer dados para o estabelecimento de padrões, orçamentos e outras formas de previsões, e num estágio seguinte, acompanhar o que efetivamente aconteceu para que se possa comparar o projetado versus realizado. Com relação à decisão, o seu papel consiste na alimentação de informações sobre valores relevantes que dizem respeito às consequências de curto e longo prazo, sobre medidas de corte de produtos, fixação de preços de venda, opção de compra, fabricação ou terceirização.

O autor destaca ainda que esses dois últimos campos da contabilidade de custos não conseguiram explorar todo o seu potencial e, desse modo, muitas empresas negligenciaram estes objetivos que, para ele, são os mais importantes da contabilidade de custos. Para dar suporte a estes três objetivos, a contabilidade de custo é constituída por um sistema de custos. O sistema de custos é formado por três subsistemas: sistema de custeio, sistema de acumulação de custos e o método de custeio. A função desses três subsistemas é identificar, acumular e processar os dados gerando informações de custos.

\section{MÉTODOS DE CUSTEIO}

\section{Por absorção}

Embora a conceituação acima corresponda aos fundamentos da contabilidade de custos, o método de custeio por absorção é amplamente utilizada para o processo de operação de custos hospitalares, porém compreende uma adaptação à versão básica e estende o cálculo dos custos para a totalidade de insumos, não importando se a classificação é custo ou despesa. O método de custeio por absorção, não ficando restrita apenas aos custos propriamente ditos, mas incluindo as despesas, é utilizado nos hospitais para o cálculo dos custos sob a segmentação dos centros de custos (MATOS, 2002).

No entanto, "o método de custeio por absorção é falho em muitas circunstâncias, como instrumento gerencial de tomada de decisão, porque tem como premissa básica os rateios dos chamados custos fixos, que, apesar de apresentarem lógica, poderão levar a alocações arbitrárias e até enganosas". (CRC/SP, 1995, p. 36). Por outro lado, de acordo com Padoveze (2000), o custeio por absorção, por ser um método mais conservador, pode deixar os gestores mais tranquilos, uma vez que todos os custos foram apropriados e com isso os parâmetros para a formação de preços estariam melhor embasados. 
A adoção do método de custeio mais adequado depende dos objetivos estabelecidos pela empresa. Se a empresa tiver como objetivo apenas respeitar a legislação fiscal, sem considerar as informações prestadas pela contabilidade de custos para a tomada de decisões, poderá adotar o custeio por absorção. Uma vantagem, citada por Padoveze (2000), é que o custeio por absorção pode ser menos custoso de implementar, pois não requer a separação dos custos de manufatura nos componentes fixos e variáveis. No entanto, se a empresa utiliza as informações prestadas pela contabilidade de custos para a tomada de decisões, poderá adotar de forma complementar, o custeio direto ou variável.

\section{Custeio direto}

Tendo em vista o fato de que no custeio por absorção não há a possibilidade de apurar o custo de um produto sem que se proceda ao rateio dos custos indiretos, existem dúvidas quanto à utilização deste método como ferramenta gerencial para fins de análise. Uma forma alternativa para custeamento é o método de custeio direto, também chamado de custeio variável.

Neste método ocorre apropriação somente dos custos variáveis, sejam diretos ou indiretos. Moura (2005) afirma que as vantagens proporcionadas pelo custeio variável são, principalmente, com relação à produção de informações para a tomada de decisão. Do custeio variável extrai-se a margem de contribuição, que é a diferença entre o preço de venda e o custo do produto. Essa margem é utilizada para responder a diversos questionamentos importantes dentro do processo decisório.

Padoveze (2000, p. 246) menciona que "as vantagens teóricas do custeio direto parecem mais claras e evidentes, pois tendem a não enviesar a apropriação dos custos dos produtos com rateios de custos indiretos sem base científica".O método de custeio a ser adotado depende da visão conceitual que a empresa tem sobre o método ideal de custeamento dos produtos. Assim, se a administração da organização entende que só os custos diretos devem compor o custo dos produtos, este será o método adotado. O mesmo raciocínio acontece com os demais métodos de custeamento (PADOVEZE, 2000).

\section{Custeio baseado em atividades (ABC)}

$\mathrm{O}$ custeio baseado em atividades representa uma das mais recentes ferramentas na área de gestão de custos e resultados. Segundo Ching (1997), o custeio ABC é um método para identificar os custos de um negócio ou departamento para as atividades realizadas e de verificar como estas atividades estão relacionadas para a geração de receitas e consumo dos recursos. Este método avalia o valor que cada atividade agrega para o resultado do negócio.

$\mathrm{O} A B C$ parte do princípio de que não é o produto ou serviço que consome recursos, mas sim, os recursos são consumidos pelas atividades e estas, por sua vez, são consumidas pelo produto ou serviço. Considerado muitas vezes um sistema de difícil implantação, trata-se em sua essência de uma poderosa metodologia de custeamento, que procura reduzir sensivelmente as distorções provocadas pelos sistemas tradicionais (ABBAS, 2001).

A metodologia de apuração de custos $\mathrm{ABC}$ é basicamente constituída de recursos, atividades, objetos de custos e direcionadores de custos. Os recursos são representados 
pelas despesas que transformam o dia da empresa, como por exemplo, mão-de-obra, material e tecnologia.

As atividades descrevem o que uma empresa faz, a forma como o tempo é gasto e os produtos do processo. A principal função de uma atividade é converter recursos em objetos de custos (produtos/serviços). Os objetos de custos são os produtos ou serviços oferecidos pela empresa (ABBAS, 2001; RAIMUNDINI, 2006). Por meio do ABC, os gestores podem obter informações operacionais importantes para a administração dos serviços e dados de custos para o sistema de reembolso dos serviços prestados.

Pode-se apurar os custos de seus serviços com mais fidedignidade; determinar a eficiência e a eficácia das atividades executadas; identificar novas atividades, com a finalidade de melhorar o desempenho da empresa no futuro; detectar as atividades que estão onerando os serviços; determinar quais atividades podem ser executadas por terceiros com menor custo e maior eficiência e servir como base para novas estratégias competitivas (ABBAS, 2002).

Segundo Rosa e Santos (2003), o ABC é um sistema capaz de proporcionar subsídios para melhor gestão administrativa, desde que a cultura organizacional seja trabalhada para que haja aceitação da nova filosofia de custos e de trabalho por todas as pessoas envolvidas, de cujas informações o sistema depende para um funcionamento preciso.

A estrutura administrativa deve deixar de ser funcional e tornar-se uma estrutura que identifique as atividades. É recomendável que todos os profissionais estejam envolvidos no processo para se obter êxito. Os recursos internos, como a infra-estrutura da organização inadequada e a falta de profissionais especializados para implantar e manter o sistema ABC pode inviabilizar a adoção deste sistema. Estas dificuldades podem ser a possível causa de que a abordagem de custeio por absorção é a mais frequentemente adotada pelas organizações hospitalares, com o sistema de apropriação por centro de custo.

\section{Apropriação por centro de custos hospitalares}

A adoção do custeio por absorção visa, sobretudo, a apuração do custo dos produtos ou serviços produzidos pela empresa. Para isto, é recomendável a clareza sobre a extensão de cobertura dos insumos utilizados para o custeio dos serviços, assim como, a identificação da unidade de produção utilizada para a determinação das referências de custos. Neste sentido, a organização terá sua segmentação das unidades de produto ou serviços, em geral departamentos, denominada centro de custo.

Na maioria das vezes um departamento é um centro de custos onde são acumulados os custos indiretos para posterior alocação aos produtos, quando referentes à produção, ou a outros departamentos, quando referentes a serviços. Entretanto, pode haver diversos centros de custos dentro de um departamento.

Segundo Bruni e Famá (2002), as principais razões da gestão de custos são referentes à determinação do lucro e ao controle das operações. Para facilitar o controle dos custos incorridos, muitas empresas preferem alocá-los aos centros de custos ou aos departamentos da organização. Estes departamentos facilitam e melhoram o processo de alocação dos gastos aos produtos, uma vez que há um responsável pelos custos incorridos. 
Os hospitais, em geral, estão organizados em departamentos, setores, seções, para os propósitos da produção dos serviços médicos. Segundo Martins (2001, p. 53), "essa estrutura é básica para a acumulação dos custos departamentais, seu controle e a determinação dos custos dos procedimentos médicos por paciente".

Uma das segmentações mais comuns aplicadas a uma organização hospitalar refere-se aos conceitos de centros de custos produtivos e centros de custo auxiliares e administrativos. Esta definição e a estruturação deve levar em conta a organização das atividades operacionais, a estrutura organizacional, a departamentalização existente e a forma com que as informações de custo atendem ao modelo de gestão do hospital (MATOS, 2002).

Os hospitais, em geral, estão organizados em departamentos, setores, seções, para os propósitos da produção dos serviços médicos. Segundo Martins (2001, p. 53), "essa estrutura é básica para a acumulação dos custos departamentais, seu controle e a determinação dos custos dos procedimentos médicos por paciente".

Os departamentos de produção médica são aqueles em que os pacientes passam por eles e são geradores de receitas, como por exemplo: centros cirúrgicos, unidade de terapia intensiva (UTI), radiologia, entre outros. Departamentos auxiliares são aqueles em que os pacientes não passam por eles e não geradores de receitas, como por exemplo: farmácia, nutrição, administração, entre outros (MARTINS, 2001).

Em outras palavras, "os centros de custo produtivos são representados pelas unidades de produção do hospital, cuja função corresponde à prestação de um serviço ao paciente e que compreenda uma atividade objeto de remuneração pelos serviços prestados". (MATOS, 2002, p. 102).

Um hospital geral com uma prestação de serviços básica, os centros de custo produtivos podem ser, por exemplo: Clínica Médica, Clínica Cirúrgica, Maternidade, Pediatria, Centro Cirúrgico, UTI, Pronto Socorro, Ambulatório e Laboratório. Os centros de custos auxiliares e administrativos correspondem aos serviços de apoio às funções de natureza administrativa. Os serviços produzidos por essas unidades não são remunerados especificamente pelos pacientes. Têm o papel de prestação de serviço interno aos centros produtivos.

A definição de uma estrutura de centros de custos deve ser precedida por um diagnóstico das operações, da estrutura física e organizacional específico de cada organização, de modo que os centros de custos sejam segmentados de modo adequado, garantindo a qualidade na informação que será utilizada para avaliação e controle dos recursos (MATOS, 2002). Os critérios e métodos de rateio também devem ser utilizados de modo coerente com as características da organização, com o objetivo de determinar o custo final de produtos e serviços o mais próximo possível da realidade.

\section{Critérios e métodos de rateio}

A utilização da abordagem de custeio por absorção pressupõe a utilização de critérios de apropriação ou rateio de custos. Estes rateios abrangem os custos indiretos e os custos dos centros de custo auxiliares e administrativos, com o objetivo de determinar o custo final dos produtos e serviços de cada unidade de produção dos centros de custo produtivos. 
De acordo com Martins (2003, p. 79), “todos os custos indiretos só podem ser apropriados, por sua própria definição, de forma indireta aos produtos, isto é, mediante estimativas, critérios de rateio, previsão de comportamento de custos, etc".

No entanto, todas estas formas possuem um certo grau de subjetivismo, sempre existindo arbitrariedade nas alocações, em alguns em nível aceitável, em outros só é aceito por falta de melhores alternativas viáveis. Os critérios de rateio para alocação dos custos indiretos, auxiliares e administrativos definem o estabelecimento das condições de distribuição dos custos, de modo a representar um parâmetro que permita a geração de um custo final dos produtos ou serviços, com um grau de confiança aceitável.

Segundo Matos (2002, p. 107), "a utilização de critérios de rateio tem sido objeto de discussão sobre sua validade, em razão do nível da arbitrariedade que eles compreendem". Muitos profissionais afirmam que é impossível apropriar os custos diretos e os custos dos centros auxiliares e administrativos com precisão, devido à dificuldade de se encontrar critérios de rateio que permitam esse nível de condições.

Martins (2001) afirma que o entendimento dos métodos para rateio dos custos indiretos de produção e das despesas dos departamentos auxiliares produtivos é de fundamental relevância. Estes custos são a parte invisível do procedimento médico, onde somente um parâmetro determinado adequadamente permitirá a alocação lógica desses gastos.

As características dos serviços hospitalares, a preocupação de identificação de parâmetros especializados e específicos, em que não são utilizados apenas critérios gerais de apropriação de custos industriais (horas/mão-de-obra direta, horas/máquina, entre outros), como direcionadores de distribuição dos custos indiretos e dos centros de custos auxiliares e administrativos, reduzem o grau de arbitrariedade característico desse mecanismo de apropriação (MATOS, 2002).

Alguns itens dos custos indiretos da produção médica e de custos dos departamentos auxiliares, conforme Martins (2001) esclarece, tendem a variar segundo a produção médica, enquanto outros itens permanecem constantes, independentemente, da produção.

Para o rateio dos custos indiretos é necessária à definição dos critérios de rateio específicos a cada um dos itens identificados sob estas condições, como o exemplo abaixo:

\begin{tabular}{|c|c|}
\hline Custos indiretos & Critérios de rateio \\
\hline Aluguel ................................... & Área ocupada $\left(\mathrm{m}^{2}\right)$ \\
\hline Depreciação . & Área ocupada $\left(\mathrm{m}^{2}\right)$ \\
\hline 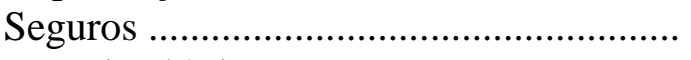 & Área ocupada $\left(\mathrm{m}^{2}\right)$ \\
\hline 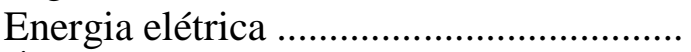 & Consumo de energia (\%) \\
\hline Água . & Consumo de água (\%) \\
\hline (2) & Número de ramais \\
\hline 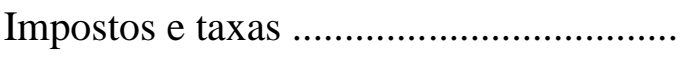 & Área ocupada $\left(\mathrm{m}^{2}\right)$ \\
\hline Outros custos e despesas .......................... & Número de funcionários \\
\hline
\end{tabular}

Figura 1: Critérios de rateio de custos indiretos

Fonte: Matos (2002, p. 108).

$\mathrm{Na}$ estruturação do sistema de custos, nos conceitos pertinentes à absorção, deverão ser constituídos de acordo com as características de cada organização hospitalar. Com relação 
ao exemplo referente à ilustração 2, algumas situações sujeitas a diferentes interpretações estão representadas pelas seguintes condições: utiliza-se a área ocupada $\left(\mathrm{m}^{2}\right)$ para o rateio da depreciação e seguros porque referem-se às edificações da empresa. Para a geração dos dados de consumo de energia e água, a orientação é que seja utilizada análises das proporções de consumo indicados por profissionais técnicos que tenham conhecimento para uma estimativa bastante aproximada dos indicadores de utilização desses insumos. $\mathrm{O}$ rateio dos custos auxiliares e administrativos, quando aplicado ao custeio por absorção, corresponde à distribuição de todos os valores registrados nessas unidades para os centros de custo produtivos, permitindo a apropriação dos custos operacionais ao produto ou ao serviço (CRC/SP, 1995).

À medida que se completa o rateio dos centros de custos auxiliares e administrativos, encerra-se o ciclo de registros de custos dos produtos ou serviços objetos de venda aos pacientes, no caso hospitalar, cuja produção ocorre apenas nos centros produtivos. A figura abaixo demonstra, a título de exemplificação, como alguns critérios de apropriação de custos auxiliares e administrativos podem ser apropriados:

\begin{tabular}{|c|c|}
\hline Centros de custos auxiliares e administrativos & Critério de rateio \\
\hline Serviços de Nutrição e Dietética ................. & Número de refeições \\
\hline 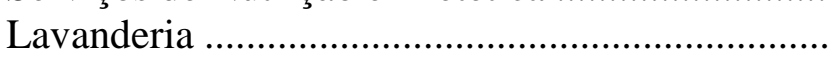 & Quilos de roupa \\
\hline Central de Material Esterilizado . & Volumes processados \\
\hline Limpeza & Área ocupada $\left(\mathrm{m}^{2}\right)$ \\
\hline Almoxarifado & Número de requisições \\
\hline Manutenção ... & Horas de manutenção \\
\hline Faturamento & Faturamento $(\%)$ \\
\hline Contabilidade .... & Custos diretos $(\%)$ \\
\hline 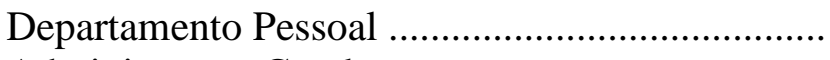 & Número de funcionários \\
\hline 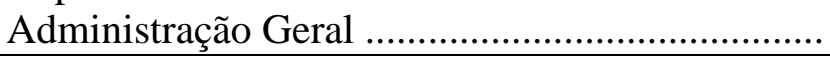 & Número de funcionários \\
\hline
\end{tabular}

Figura 2: Critérios de rateio de custos auxiliares e administrativos Fonte: Matos (2002, p. 111).

Para a definição adequada dos critérios a serem adotados existe a necessidade de análise específica para cada hospital. O mesmo critério de rateio pode ser adequado a uma instituição e não para outra, devido às peculiaridades de cada uma.

O grau de dificuldade para a geração dos dados relevantes para o sistema de apuração de custos é outro fator que influencia nos critérios de rateio a ser adotados. Como o processo de rateio dos centros de custos auxiliares e administrativos consiste na transferência dos custos dessas unidades para os centros produtivos, é recomendável a determinação da abrangência como requisito, por meio dos métodos de rateio.

\section{Construção de um sistema de custos hospitalares}

O principal objetivo da administração de um hospital é o equilíbrio entre os gastos e as receitas para que a instituição possa permanecer funcionando e oferecendo atendimento de qualidade ao paciente. O sistema de gestão de custos em conjunto com o plano de contas contribui para a manutenção desse objetivo, uma vez que deve ser capaz de calcular os custos das receitas; proporcionar meios para a análise dos estoques de materiais médicos e medicamentos; indicar a eficiência dos equipamentos; auxiliar na eliminação de desperdícios, com o objetivo de minimizar custos; auxiliar no estabelecimento de preços de 
venda das taxas, dos materiais médicos, dos medicamentos e dos procedimentos médicos (MARTINS, 2001).

Os instrumentos necessários para que as informações referentes ao sistema de custos tenham a precisão desejada, segundo Martins (2001), são:

$\checkmark$ Plano de contas: é o instrumento que possibilita o controle dos custos e despesas hospitalares e deve permitir a identificação dos responsáveis pela incidência. Fatores que devem ser observados: as contas devem ser organizadas para oferecer informação completa com a mínima necessidade de análises suplementares; os títulos das contas devem ser refletir com precisão os tipos de custos e despesas do hospital.

$\checkmark$ Unidade de custo: a seleção da unidade de custo é fundamental para a determinação, controle e análise dos custos hospitalares. Essa unidade deve ter o tamanho adequado para facilitar o seu monitoramento.

$\checkmark$ Cálculo dos custos: após o estabelecimento da unidade de custo, os dados devem ser agrupados para fornecer o custo unitário do procedimento médico por paciente.

Apresentada a fundamentação sobre os diversos aspectos relacionados à gestão de custos em organizações, com o aprofundamento do foco nas organizações hospitalares, levantamento dos conceitos teóricos com a análise e comparação entre os diversos autores que abordam o assunto, o item a seguir apresentará os procedimentos metodológicos que foram utilizados na realização do estudo.

\section{IMPLEMENTAÇÃO DE UM SISTEMA DE APURAÇÃO DE CUSTOS NO CENTRO DE PESQUISAS ONCOLÓGICAS (CEPON)}

O Centro de Pesquisas Oncológicas (CEPON) é um órgão público estadual, vinculado à Secretaria de Estado da Saúde (SES), na área da oncologia, especializado no tratamento de pacientes com câncer. Foi criado em 1974, no Hospital Governador Celso Ramos. Ao ganhar espaço e importância no Estado de Santa Catarina, em 1982, passou a ser Unidade da Secretaria de Estado da Saúde para atendimento aos pacientes oncológicos (CEPON, 2003; 2006).

Em 1994, por meio de convênio firmado entre a Secretaria de Estado da Saúde (SES) e a então criada Fundação de Apoio ao Hemocentro de Santa Catarina e Centro de Pesquisas Oncológicas (FAHECE) é adotado o modelo de gestão fundacional privado para administrar os recursos gerados pelo CEPON. A parceria estabelecida com a FAHECE permitiu autonomia na gestão de recursos financeiros e proporcionou maior qualidade na prestação de serviços (FAHECE, 2007).

Em 2007, a FAHECE foi qualificada como Organização Social e foi firmado o Contrato de Gestão para o fomento e execução da assistência oncólogica com o estabelecimento de metas e indicadores de desempenho, cujo principal objetivo é disponibilizar à população acesso ao atendimento oncológico com qualidade.

Devido a pesquisas desenvolvidas permanentemente na área, a atualização da equipe em relação a novos tratamentos é indispensável para oferecer o melhor e mais moderno atendimento ao paciente. A descoberta de novos medicamentos para o tratamento de câncer é um processo contínuo na busca da cura definitiva e a qualificação da equipe é fator determinante para acompanhar a evolução. 
Em 2013, o CEPON redefiniu a sua missão, visão e valores definidos com a participação da alta direção, lideranças formais e informais das diversas áreas e representantes de instituições vinculadas, tais como a Fundação de Apoio e a Secretaria da Saúde:

$\checkmark$ Missão: Prestar assistência integral, humanizada e de qualidade ao paciente com câncer, no âmbito do SUS, em Santa Catarina.

$\checkmark$ Visão: Ser um centro de referência em alta complexidade oncológica (CACON) até 2016, promovendo ações de ensino e pesquisa.

Os serviços oferecidos pelo CEPON visam contemplar, prioritariamente, o paciente com câncer oriundo do Sistema Único de Saúde (SUS). Oferece-se aos pacientes tratamentos modernos e alta tecnologia, como por exemplo, a Unidade de Radioterapia que dispõe de modernos equipamentos, de última geração, desenvolvidos para o tratamento radioterápico do paciente com câncer.

O quadro abaixo mostra os principais serviços oferecidos pelo CEPON, as principais características e os benefícios que proporcionam aos seus usuários:

\section{Tabela 1: Serviços oferecidos pelo CEPON}

\begin{tabular}{|c|l|}
\hline SERVIÇO & \multicolumn{1}{|c|}{ CARACTERÍSTICAS/BENEFÍCIOS } \\
\hline Ambulatorial & $\begin{array}{l}\text { Atende pacientes do SUS procedentes de todo o Estado de SC para } \\
\text { realização de consultas nas diversas especialidades oncológicas } \\
\text { (Oncologia Clínica, Oncohematologia, Cirurgia de Cabeça e Pescoço, } \\
\text { Oncourologia, Oncoginecologia, Serviço de Adolescentes e Jovens, } \\
\text { etc.) e realização do tratamento quimioterápico, radioterápico, centro } \\
\text { cirúrgico ambulatorial e pronto-atendimento, bem como, atendimento } \\
\text { pela equipe multiprofissional (nutricionista, psicólogo, psiquiatra, } \\
\text { assistente social, terapeuta ocupacional, etc.) }\end{array}$ \\
\hline Internação & $\begin{array}{l}\text { Atende, exclusivamente, pacientes do SUS, que necessitam de } \\
\text { internação para realização de quimioterapia, intercorrências clínicas ou } \\
\text { cuidados paliativos. Oferece atendimento humanizado com equipe } \\
\text { multiprofissional. }\end{array}$ \\
\hline Intespitalar \\
Domiciliar & $\begin{array}{l}\text { Atende em domicílio pacientes do CEPON (SUS) cadastrados no } \\
\text { programa que não apresentam mais possibilidades terapêuticas de cura. } \\
\text { O paciente visitado, regulamente, por equipe multiprofissional } \\
\text { (médico, equipe de enfermagem, assistente social, entre outros) que } \\
\text { presta o atendimento, fornece os medicamentos e quando necessário, a } \\
\text { dieta específica. }\end{array}$ \\
\hline Transplante & $\begin{array}{l}\text { Realiza transplantes de medula óssea autólogos, isto é, o doador é o } \\
\text { próprio paciente. O CEPON é o único órgão a oferecer este transplante } \\
\text { em SC. }\end{array}$ \\
\hline Medula Óssea
\end{tabular}

Fonte: CEPON

O Centro de Pesquisas Oncológicas (CEPON), não possui um sistema de gestão de custos estruturado. Os dados referentes a custos são registrados sob a responsabilidade da área financeira da organização, porém não utilizados de modo sistemático e não são produzidas informações que auxiliem na tomada de decisão ou que monitorem os gastos.

Os custos diretos, referentes a pedidos de almoxarifado (material técnico, medicamentos e material de expediente) e compras diretas, em situações excepcionais, são apropriados às 
unidades do CEPON, dividas em: ambulatório, radioterapia, unidades de internação, centro cirúrgico e transplante de medula óssea, entre outros.

\section{RESULTADOS ENCONTRADOS E A SUGESTÃo DE MÉTODO DE RATEIO POR CENTRO DE CUSTO}

\section{Resultados Encontrados}

A apuração de custos é a técnica gerencial que permite subsidiar as decisões a serem adotadas diante da complexidade da gestão administrativa e aos gastos crescentes das ações de saúde.

O sistema de custos e seu acompanhamento proporciona ao gestor o conhecimento de seu orçamento, pois quando não se tem a informação sobre quanto custam os insumos e quanto se gasta em processos, não se pode decidir o que vai fazer, em que quantidade minimizar as despesas e nem mesmo sugerir o orçamento.

Com base nos argumentos teóricos e empíricos, discutidos pelos estudiosos da área será apresentada, para o CEPON, a proposta para a implementação do sistema de custeio por absorção.

Os principais objetivos para a implementação do sistema de custos por absorção são:

$\checkmark$ Informar a participação de cada setor (ou centro de custo) no gasto total de operação da unidade;

$\checkmark$ Conhecer a relação entre gastos realizados por centro de custo e os serviços produzidos visando a racionalização administrativa (custo / produto);

$\checkmark$ Detectar variações nos custos dos serviços e determinar suas prováveis causas, a partir da comparação dos custos de um mesmo serviço em diferentes unidades ou, para, a mesma unidade, em períodos diferentes;

$\checkmark$ Montar rotinas para o processamento das informações relativas à relação recursos/produção, de modo a subsidiar a projeção de gastos futuros (custos observados e demanda esperada) e a elaboração de orçamentos programa;

$\checkmark$ Fixar valores de referência para os serviços prestados, para que possam servir como base para assinatura de convênios com outras instituições;

$\checkmark$ Aprofundar o conhecimento da estrutura real, dos recursos face aos serviços efetuados, de modo a permitir a definição de normas operacionais e a projeção dos recursos necessários para atender a demanda;

$\checkmark$ Fornecer elementos para elaboração ou readequação dos mecanismos administrativos e técnicos de controle interno tanto de recursos humanos quanto de recursos materiais.

A implementação do sistema de custos pressupõe a necessidade de alguns pré-requisitos, que deverão ser preenchidos pelo CEPON para viabilizar a existência de um sistema de apuração que venha ao encontro das necessidades organizacionais:

$\checkmark$ Existência de amplo sistema de informações que colete e organize os dados sobre produção dos serviços da unidade; 
$\checkmark \quad$ Estabelecimento de um fluxo de informações que abranja dados financeiros (despesas com pessoal, material de consumo, serviços de terceiros, entre outros);

$\checkmark$ Identificação das informações necessárias e dos setores do hospital responsáveis pela emissão dessas informações: escolha do nível de desagregação no sistema de apuração de custos a utilizar; definição da origem e destino das ações; e estabelecimento de fluxo contínuo e articulado entre os centros de custos e o núcleo de custos;

$\checkmark$ Supervisão, acompanhamento e análise permanentes dos resultados da apuração de custos, haja vista que são instrumentos para subsidiar tomada de decisões.

$\checkmark$ No entanto, o êxito da implantação de custos vai depender da utilização de uma estratégia que deverá contemplar, essencialmente:

$\checkmark$ Sensibilização da direção para necessidade, utilidade e importância da apuração de custos hospitalares;

$\checkmark$ Organização de um núcleo de custos como estrutura organizacional que opere o sistema de custos hospitalares;

$\checkmark$ Sensibilização de toda a equipe para a importância do sistema de custos e treinamentos do pessoal sob forma de treinamento em serviço, para apuração de custo;

$\checkmark$ Constituição de um sistema de informações.

Para a devida implementação do sistema de apuração de custos pelo método de custeio por absorção identificou-se algumas das etapas, ou seja, os passos necessários:

1. Identificação dos centros de custos da unidade de suas respectivas unidades de produção. A partir da estrutura administrativa do CEPON, definiu-se todos os setores que realizam atividades, ou seja, que produzem serviços quantificáveis. Esta produção é que caracteriza o centro de custo que vai ser a base dos cálculos de custos. Para ter certeza de um determinado setor do CEPON pode ser considerado um centro de custo, três perguntas tiveram que ter respostas claras e objetivas: o que produz, quanto produz e quanto custa o produto? Para facilitar os cálculos de custos, os centros de custos são classificados em duas categorias: centro de custo final, isto é, setor em que o serviço está relacionado aos objetivos finais da instituição e centro de custo de apoio, que são os setores relacionados às atividades complementares, os quais possibilitam $\mathrm{o}$ desenvolvimento das atividades dos centros de custo finais. Os centros de custo final ou produtivos do CEPON podem ser identificados como: Ambulatório; Quimioterapia; Internação Hospitalar; Radioterapia; Transplante de Medula Óssea (TMO); Laboratório Anatomopatológico; Programa de Internação Domiciliar (PID); Centro Cirúrgico, Ambulatório de Intercorrências;

2. Levantamento e alocação dos custos diretos e indiretos com a apuração dos custos operacionais e sua alocação no respectivo centro de custo. Entende-se por custos operacionais ou auxiliares, os valores obtidos ao se calcular os serviços utilizados para produzir outros serviços. Neste item podem ser incluídas as despesas com: administração (direção, gerências, assessorias, demais setores administrativos), condomínio (vigilância, corredores, banheiros, vestiários, casa das máquinas, pátio/jardins, capela, estacionamentos), limpeza; manutenção predial; reprografia (protocolo), informática; SAME (Serviço arquivo médico), farmácia, central de diluição de medicamentos, serviço Social, biblioteca e nutrição. A metodologia para apuração destes custos será vista no próximo item, referente aos métodos de rateio sugeridos; 
3. Levantamento da produção de cada um dos centros de custos identificados. A partir da identificação das informações necessárias para o sistema de custos e do levantamento dos setores do CEPON responsáveis por estas informações, a coleta e a organização dos dados sobre a produção dos serviços podem ser iniciadas;

4. Cálculo dos custos diretos e os custos finais/totais de cada centro de custo. Os custos diretos são compostos pela soma dos custos fixos e custos variáveis. Os custos indiretos referem-se aos custos que ocorrem em outras áreas, mas precisam ser incorporados aos custos de um centro determinado. Os custos totais são compostos pela soma dos custos diretos e os custos indiretos:

Os custos fixos são aqueles de independem do volume de produção do centro de custo. Custos variáveis são aqueles que se alteram em função da quantidade de serviços produzidos. Os principais custos fixos e variáveis do CEPON foram relacionados na tabela a seguir:

Tabela 2: Custos fixos e variáveis CEPON

\begin{tabular}{|c|c|}
\hline CUSTOS FIXOS & CUSTOS VARIÁVEIS \\
\hline $\begin{array}{l}\text { Salários e encargos sociais } \\
\text { Serviços terceirizados } \\
\text { Contratos manutenção de } \\
\text { equipamentos } \\
\text { Seguros } \\
\text { Impostos e taxas } \\
\text { Prêmio por desempenho } \\
\text { Aluguel bens imóveis } \\
\text { Aluguel de bens móveis }\end{array}$ & $\begin{array}{l}\text { Medicamentos } \\
\text { Materiais técnicos, Materiais de expediente } \\
\text { Materiais de limpeza, Outros materiais de } \\
\text { consumo } \\
\text { Gases medicinais } \\
\text { Alimentação (funcionários/pacientes) } \\
\text { Lavanderia, Energia elétrica, Água e Telefone } \\
\text { Combustíveis, lubrificantes e manutenção } \\
\text { veículos } \\
\text { Transporte de resíduos } \\
\text { Correio, Fretes, Atividades sociais } \\
\text { Reprografia, Manutenção de móveis e } \\
\text { equipamentos de informática. }\end{array}$ \\
\hline
\end{tabular}

Fonte: CEPON.

5. Análise dos resultados. Esta etapa tem como objetivo medir os resultados das relações entre os recursos utilizados e as metas alcançadas, por meio da construção de indicadores que:

$\checkmark$ Verifiquem a produtividade obtida, ou seja, a relação recursos/serviços;

$\checkmark$ Apurem a de eficiência dos processos utilizados;

$\checkmark$ Avaliem a racionalização do uso de insumos e recursos humanos;

$\checkmark$ Comparem os recursos financeiros aplicados e os serviços obtidos com o tempo gasto para a finalização desses serviços.

Diante dos conceitos abordados na revisão de literatura, bem como, as características e especificidades do CEPON, a seguir apresenta-se a sugestão para métodos de rateio dos custos. 


\section{Sugestão de método de rateio por centro de custo}

O método de custeio por absorção pressupõe a utilização de instrumentos de apropriação ou rateio de custos. Os rateios compreendem os custos indiretos e os custos dos centros auxiliares de modo que o custo final seja representado pelos centros de custos produtivos.

Os rateios são considerados, de certo modo, arbitrários, pois nem sempre se consegue alocar os custos de maneira que contemple o real percentual que cabe a cada centro de custo, adotando-se critérios, por vezes, subjetivos. No entanto, a coerência na alocação pode minimizar distorções. No quadro, apresenta-se a proposta de critérios para rateio dos custos indiretos e auxiliares do CEPON:

Tabela 3: Critérios rateio custos

\begin{tabular}{|l|l|}
\hline \multicolumn{1}{|c|}{ CUSTO } & \multicolumn{1}{c|}{ CRITÉRIO DE RATEIO } \\
\hline Água & Proporção de consumo (\%) \\
\hline Energia elétrica & Proporção de consumo (\%) \\
\hline Seguro predial & Área ocupada $\left(\mathrm{m}^{2}\right)$ \\
\hline Telefone (ligações via central telefônica) & Número de ramais \\
\hline Impostos/seguros (prediais e territoriais) & Área ocupada $\left(\mathrm{m}^{2}\right)$ \\
\hline Alimentação & Número de refeições \\
\hline Ar condicionado central (manutenção) & Área ocupada $\left(\mathrm{m}^{2}\right)$ \\
\hline Transporte de resíduos & $\begin{array}{l}\text { Resíduo comum: área ocupada }\left(\mathrm{m}^{2}\right) \\
\text { Resíduo infectante: proporção utilização } \\
(\%)\end{array}$ \\
\hline
\end{tabular}

Fonte: CEPON.

A distribuição dos custos auxiliares e administrativos aos centros de custo produtivos pode ocorrer dentro de três metodologias, conforme Matos (página 39): rateio simples, rateio sequencial e rateio duplo. O rateio simples apresenta algumas imprecisões e o método de rateio duplo permite a obtenção de parâmetros mais precisos, no entanto, exige um grau maior de aprofundamento e complexidade. Neste sentido, optou-se por sugerir para o CEPON o método intermediário, ou seja, o rateio sequencial.

Sob a orientação deste método de rateio, deve-se utilizar uma sequência de rateio com prioridade às unidades em que a atividade é mais abrangente, isto é, trabalham para um maior número de centros de custo até que sejam contemplados todos os centros de custos, com alocação aos centros de custo produtivos.

Com a adoção de uma planilha de processamento de custos hospitalares no CEPON, poderão ser elaborados relatórios gerenciais, tais como, composição e evolução dos custos, custo total e unitário dos serviços, entre outros, com o objetivo de avaliação e análise dos custos pelos gestores para subsidiar a tomada de decisão.

\section{CONSIDERAÇÕES FINAIS}

Tendo em vista o objetivo geral do presente artigo, que é apresentar um estudo para a implementação de um sistema de apuração de custos no CEPON, faz-se necessário alinhar os aspectos mais relevantes ao tema. 
Percebe-se que os aspectos relacionados aos crescentes gastos públicos nas organizações, aos problemas relacionados ao financiamento desses gastos, à grande necessidade e ainda pequena disseminação de métodos adequados de apuração ou mensuração de custos, à importância de seu gerenciamento, de seu controle e de seu uso para decisão, a análise e escolha de programas e estabelecimento de políticas para a área da saúde fazem com a gestão de custos hospitalares seja uma ferramenta indispensável para o modo modelo de administração hospitalar.

Sendo assim, para uma gestão voltada para a eficiência, eficácia e efetividade, a otimização dos recursos tornou-se indispensável para a manutenção da qualidade e a sobrevivência das organizações hospitalares. Os hospitais deixaram de ser entidades assistenciais despreocupadas com as técnicas de gestão administrativa. Tiveram que se adequar a uma nova realidade, em que os recursos se tornaram cada vez mais escassos para uma demanda crescente de pacientes.

Neste sentido, mostrou-se a importância da aplicação de um sistema de apuração de custos nas organizações hospitalares. Conhecer o verdadeiro custo de todas as atividades que compõe cada serviço torna-se um diferencial competitivo de um hospital em seu mercado. Assim como os demais segmentos de negócios, a área hospitalar demanda uma administração profissional.

Verificou-se que os métodos de apuração de custos sofrem frequentes adequações e novos modelos surgem, de modo a proporcionar metodologias mais adequadas e precisas de mensuração. Apesar da importância, percebeu-se que poucas unidades hospitalares adotam métodos de apuração mais sofisticados, como o ABC, por exemplo, optando pelo custeio por absorção. Diante disso, tendo em vista as características da organização, optou-se por sugerir a implementação de um sistema de apuração de custos baseado no custeio por absorção com alocação aos centros de custo.

As etapas deste processo envolvem desde a necessidade da constituição de um sistema e fluxo de informações precisas que abranjam dados financeiros e de custos, sensibilização da direção e demais áreas para a importância do sistema de apuração de custos, organização de um núcleo de custos até passos específicos para a implementação, como a definição dos centros de custos e apuração e alocação dos custos operacionais de cada um deles, o levantamento da produção de cada centro, o cálculo dos custos diretos e dos custos totais e, finalmente, a análise dos resultados.

Por meio da análise dos resultados pode-se identificar a produtividade obtida, ou seja, a relação recursos versus produto/serviço, a eficiência dos processos e a racionalização no uso dos recursos, entre outras informações importantes à tomada de decisão do gestor.

Como sugestões para trabalhos futuros, pode-se aprofundar o estudo identificando métodos de rateio mais apropriados, após a implementação do sistema de apuração de custos com o método custeio por absorção, pois com a prática pode-se identificar deficiências no processo e com isso aplicar as devidas medidas corretivas; a aquisição de software específico para a gestão de custos hospitalares, bem como, a elaboração de um estudo para a adoção do método de custeio baseado em atividades (ABC), que é uma evolução dos métodos tradicionais e que pode ser mais adequada às organizações hospitalares que já possuem uma cultura de custos implementada e a uma estrutura organizacional adequada. 


\section{REFERÊNCIAS BIBLIOGRÁFICAS}

1. ABBAS, K. Gestão de custos em organizações hospitalares. Florianópolis, 2001. 155 p. Dissertação (Mestrado em Engenharia de Produção). Programa de Pós-Graduação em Engenharia de Produção, Universidade Federal de Santa Catarina, 2001.

2. ARTMANN, Elizabeth and URIBE RIVERA, Francisco Javier. A démarche stratégique (gestão estratégica hospitalar): um instrumento de coordenação da prática hospitalar baseado nos custos de oportunidade e na solidariedade. Ciênc. saúde coletiva [online]. 2003, vol.8, n.2, pp. 479-499. ISSN 1413-8123. Disponível em: <www.scielo.org/php/index.php >. Acesso em: ago. 2010.

3. BITTENCOURT, O. N. da S. O emprego do método de custeio baseado em atividades: Activity-Based Costing $(\mathrm{ABC})$ : como instrumento de apoio à decisão na área hospitalar. Porto Alegre, 1999. 205 p. Dissertação (Mestrado). Programa de PósGraduação em Administração. Universidade Federal do Rio Grande do Sul. Disponível em: 〈http://www.volpi.ea.ufrgs.br/teses_e_dissertacoes> Acesso em: 1 abr. 2007.

4. BRUNI, A. L; FAMÁ, R. Gestão de custos e formação de preços: com aplicações na calculadora HP 12C e excel. São Paulo: Atlas, 2002.

5. CAllado, A. A. C; CAlladO, A. L.C. Custo na Tomada de Decisões em Empresas Rurais. IN: Congresso Brasileiro de Gestão Estratégica de Custos, V., Fortaleza, 1998. Anais. Sebrae/CE, v.1.

6. CAMACHO, Reinaldo Rodrigues and ROCHA, Welington. Custeio-alvo em serviços hospitalares um estudo sob o enfoque da gestão estratégica de custos. Rev. contab. finanç. [online]. 2008, vol.19, n.47, pp. 19-30. ISSN 1808-057X. Disponível em: <www.scielo.org/php/index.php>. Acesso em: ago. 2010.

7. CARDOSO, J. G. Modelos de gestão em organizações hospitalares. 2006. $67 \mathrm{f}$. Apostila - (Curso de pós-graduação em administração hospitalar e empreendimentos de saúde: ênfase em organizações públicas) - Escola de Saúde Pública de Santa Catarina, Florianópolis, 2006.

8. CECÍlLIO, L. C. de O. A modernização dos hospitais públicos: o difícil exercício da mudanças. Revista de administração pública. Rio de Janeiro, v.31, n. 3, p. 36-47, maio/jun. 1997.

9. CEPON. Relatório de gestão 1999-2002. Florianópolis: CEPON, 2003.

10. Relatório estatístico trimestral: outubro a dezembro 2005. Florianópolis: CEPON, 2006.

11. CHING, H. Y. Gestão baseada em custeio por atividades: activity based management. 2. ed. São Paulo: Atlas, 1997.

12. CRC/SP (CONSELHO REGIONAL DE CONTABILIDADE ESTADO DE SÃO PAULO). Custo como ferramenta gerencial - 8. São Paulo: Atlas, 1995.

13. FAHECE. Fundação de apoio ao HEMOSC e CEPON. Serviço de Oncologia CEPON. Disponível em: 〈http://www.fahece.org.br〉 Acesso em: 23 mar. 2012.

14. FERNANDES, L. O. Custo hospitalar. São Paulo: LN Impressos Padronizados, 1993.

15. GIL, A. C. Como elaborar projetos de pesquisa. 3. ed. São Paulo: Atlas, 1996. 
16. LEONE, George Sebastião Guerra. Custos: um enfoque administrativo. 9. ed. Rio de Janeiro: Fundação Getúlio Vargas, 1992.

17. Curso de contabilidade de custos. 2 ed. São Paulo: Atlas, 2000 .

18. MARTINS, D. Gestão financeira de hospitais. 2. ed. São Paulo: Atlas, 2001.

19. MARTINS, E. Contabilidade de custos. 9. ed. São Paulo: Atlas, 2003.

20. MARTINS, V. F. Desenvolvimento de modelo de resultados em serviços hospitalares com base na comparação entre receitas e custos das atividades associadas aos serviços. Florianópolis, 2002. 117p. Dissertação (Mestrado em Engenharia de Produção). Programa de Pós-graduação em Engenharia de Produção, UFSC, 2002. Disponível em: <http://www.teses.eps.ufsc.br> Acesso em: 30 mar. 2007.

21. MATOS, A. J. Gestão de custos hospitalares: técnicas, análise e tomada de decisão. 2. ed. São Paulo: STS, 2002.

22. MOURA, H. da S. O custeio por absorção e o custeio variável: qual seria o melhor método a ser adotado pela empresa? Sitientibus. Feira de Santana, n. 32, p. 129-142, jan./jun. 2005. Disponível em: 〈http://www.uefs.br/sitientibus> Acesso em: 01 abr. 2007.

23. NUNES, J. M; INFANTE, Maria. Administração de recursos financeiros e orçamentários. In GESTHOS (Gestão Hospitalar). Módulo III: gestão de recursos nas organizações de saúde. Brasília: Editora MS, 2002.

24. PADOVEZE, C. L. Contabilidade Gerencial: um enfoque em sistema de informação contábil. 3. ed. São Paulo: Atlas, 2000.

25. PASOLD, C. L. Prática da Pesquisa Jurídica: ideias e ferramentas úteis para o pesquisador do direito. 7. ed. Florianópolis: $\mathrm{OAB} / \mathrm{SC}, 2002$.

26. RAIMUNDINI, L; et al. Aplicabilidade do custeio baseado em atividades e análise de custos em hospitais públicos. Revista de administração. São Paulo, v. 41, n.4, p. 453465, out./nov./dez, 2006.

27. ROCHA, Welington. Da contabilidade de custos à gestão estratégica de custos. Rev. contab. finanç. [online]. 2007, vol.18, n.43, pp. 7-7. ISSN 1808-057X. Disponível em: <wWw.scielo.org/php/index.php>. Acesso em: ago. 2010.

28. ROSA, P. R. da; SANTOS, C. H. S. Gestão de custos num hospital de Santa Cruz do Sul: RS. Contabilidade Vista \& Revista. Belo Horizonte, v. 14, n. 2, p. 67-83, ago. 2003. 